\title{
Polimerização RAFT em Miniemulsão
}

\author{
Marco Antonio M. Oliveira, Márcio Nele, José Carlos Pinto \\ Programa de Engenharia Química, COPPE, UFRJ
}

Resumo: Dentre as diversas técnicas para obter polímeros de maneira controlada, a técnica de Transferência Reversível de Cadeia por Adição-Fragmentação (RAFT) é tida como uma das mais versáteis, uma vez que é compatível com uma grande quantidade de monômeros, solventes, condições reacionais e sistemas de polimerização. Utilizando essa metodologia, é possível sintetizar polímeros com diversas arquiteturas e com excelente controle do tamanho das cadeias. Neste trabalho, é apresentada uma revisão da técnica de polimerização RAFT em sistemas de miniemulsão. As principais características da técnica de polimerização RAFT e uma ampla revisão dos estudos em miniemulsão são apresentadas, abrangendo mais de 152 referências. Também é abordado nesta revisão o uso da polimerização RAFT em miniemulsão para obtenção de polímeros para aplicações biotecnológicas.

Palavras-chave: Polimerização, RAFT, miniemulsão, biotecnologia, nanopartículas.

\section{RAFT Polymerization in Miniemulsions}

\begin{abstract}
Among the many techniques used to prepare polymers in a controlled manner, reversible addition fragmentation chain transfer polymerization (RAFT) is one of the most versatile, since this technique is compatible with a large number of monomers, solvents, reaction conditions and polymerization systems. Using this methodology, it is possible to synthesize polymers with a variety of architectures and with a high level of control of the molecular weight distribution. In this work, a review of RAFT polymerizations in miniemulsion systems is presented. The main characteristics of the RAFT polymerization technique and a comprehensive review of studies in miniemulsion are presented, comprising more than 152 references. The use of RAFT miniemulsion polymerizaton to obtain polymers for biotechnological applications is also discussed in detail.
\end{abstract}

Keywords: Polymerization, RAFT, miniemulsion, biotechnology, nanoparticles.

\section{Introdução}

$\mathrm{O}$ século XX foi particularmente impactante na sociedade contemporânea, especialmente com o advento da Química Moderna e seus inúmeros avanços, como a identificação das macromoléculas ${ }^{[1,2]}$ e o desenvolvimento de inúmeras técnicas de polimerizaçãa $\mathrm{O}^{[3]}$, que criaram um novo campo de pesquisa: a Ciência de Polímeros. Esse novo campo de pesquisa permitiu a criação de uma nova classe de materiais sintéticos, vulgarmente conhecidos como plásticos, que são empregados hoje nos mais variados tipos de aplicações, incluindo desde a confecção de embalagens para alimentos até dispositivos nanométricos usados no tratamento de doenças ${ }^{[4-6]}$.

Os polímeros sintéticos são normalmente obtidos por reações de polimerização, que seguem usualmente os bem conhecidos mecanismos de polimerização em cadeia ou em etapas. Dentre os diversos processos disponíveis, as técnicas de polimerização via radicais livres (mecanismo em cadeia) são largamente empregados em plantas industriais para a síntese de polímeros. Isto se deve principalmente a algumas vantagens das reações via radicais livres frente a outros métodos de polimerização, sendo possível citar: (i) a possibilidade de usar uma larga gama de monômeros, incluindo alguns de grande interesse comercial, como o caso do estireno, metacrilato de metila e acetato de vinila; (ii) é uma técnica muito tolerante à presença de grupos funcionais contaminantes (ex. $\mathrm{OH}, \mathrm{COOH}, \mathrm{NR}_{2}, \mathrm{CONR}_{2}$ ); (iii) pode ser usada em diversas condições operacionais; (iv) já foi adaptada para diversos sistemas de polimerização, como no caso dos sistemas em solução, massa, suspensão, emulsão, entre outros; (iv) é uma técnica fácil de ser implementada e de relativamente baixo custo operacional, quando comparada a outras tecnologias disponíveis ${ }^{[3,7-10]}$.

Independentemente do sistema de polimerização ou reagentes químicos usados, os mecanismos cinéticos das reações de polimerização via radicais livres são usualmente descritos em termos de três etapas fundamentais, conhecidas como Iniciação, Propagação e Terminação, apresentadas a seguir:

Iniciação

$$
\begin{aligned}
& I \stackrel{k_{d}}{\longrightarrow} 2 R_{\bullet} \\
& R_{\bullet}+M \stackrel{k_{r}}{\longrightarrow} P_{1} \bullet
\end{aligned}
$$

Propagação

$$
P_{n} \bullet+M \stackrel{k_{s}}{\longrightarrow} P_{n+1} \bullet
$$

Terminação

$$
\begin{aligned}
& P_{n} \bullet+P_{m} \bullet \stackrel{k_{t \bullet}}{\longrightarrow} \Lambda_{n+m} \\
& P_{n} \bullet+P_{m} \stackrel{k_{f}}{\longrightarrow} \Lambda_{n}+\Lambda_{m}
\end{aligned}
$$

A primeira etapa do processo corresponde à etapa de Iniciação (Equações 1 e 2), em que são gerados os radicais livres que iniciam a reação de polimerização.

Autor para correspondência: José Carlos Costa da Silva Pinto, Programa de Engenharia Química, Instituto Alberto Luiz Coimbra de Pós-Graduação e Pesquisa de Engenharia - COPPE, Universidade Federal do Rio de Janeiro - UFRJ, Cidade Universitária, CP 68502, CEP 21941-972, Rio de Janeiro, RJ, Brasil, e-mail: pinto@peq.coppe.ufri.br 
No caso dessas reações, o centro ativo (que proporciona o crescimento da cadeia polimérica) é um radical livre. Na etapa seguinte, conhecida como Propagação (Equação 3), ocorre o crescimento da cadeia polimérica por intermédio de sucessivas incorporações de unidades monoméricas às cadeias ativas (ou vivas). $\mathrm{Na}$ etapa de Terminação (Equações 4 e 5) ocorre a perda de atividade do centro ativo, formando uma cadeia de polímero inativa (ou morta). A etapa de Terminação exerce grande influência sobre o controle do tamanho final da cadeia polimérica formada e pode ocorrer por diferentes tipos de mecanismos ${ }^{[3,11]}$.

As reações de polimerização via radicais livres são normalmente muito exotérmicas ${ }^{[3]}$ e extremamente rápidas, uma vez que as cadeias crescem por aproximadamente 1 segundo antes de se envolverem em reações de terminação, que levam à formação das cadeias poliméricas mortas ${ }^{[12]}$. Dessa forma, durante toda a reação de polimerização (que pode durar de minutos a horas) diversas cadeias são iniciadas, propagam e morrem, de forma continuada, até a completa depleção de monômero no meio reacional e/ ou fonte geradora de radicais livres ${ }^{[3]}$. Isso implica que geralmente o tamanho médio das cadeias diminui com o tempo de reação, principalmente devido à redução da concentração de monômero no meio reacional. Esse fato influencia outra característica bem marcante das reações de polimerização via radicais livres, que é formação global de cadeias bastante heterogêneas, principalmente em relação aos valores de massa molar, ocasionando altos índices de polidispersão $\left(M_{w} / M_{n}>1,5\right)^{[7]}$.

A formação de cadeias poliméricas heterogêneas aponta para uma das principais desvantagens da técnica de polimerização via radicais livres convencional, que é o pobre controle sobre a estrutura/características das moléculas sintetizadas ${ }^{[7]}$. Isso se deve à alta reatividade dos radicais presentes no meio reacional, que se envolvem espontaneamente em reações de terminação e outros tipos de reações secundárias ${ }^{[3,13]}$, que ocasionam a morte dos radicais livres e a interrupção do crescimento das cadeias poliméricas. Desta forma, devido à alta reatividade dos radicais das cadeias em crescimento e um curto intervalo entre as etapas de geração dos radicais livres e a morte da cadeia polimérica, nãoé possível controlar adequadamente a formação das cadeias poliméricas e sintetizar polímeros com arquitetura complexa (ex. copollímeros em bloco, multibloco, tipo estrela, etc.; Figura 1) e/ou polímeros com baixo índice de polidispersão $\left(M_{w} / M_{n}<1,3\right)$.
Durante o desenvolvimento da Ciência de Polímeros, alternativas mecanísticas e diferentes processos foram propostos para permitir a produção de polímeros com arquitetura complexa e bem definida. Uma dessas alternativas é constituída por um conjunto particular de polimerizações iônicas, também conhecidas como polimerizações $\operatorname{vivas}^{[3]}$. Esse tipo de reação ocorre via mecanismo em cadeia, envolvendo monômeros vinílicos. As duas principais diferenças existentes entre as reações radicalares e as reações iônicas vivas são: (i) a espécie ativa/propagadora nas reações iônicas vivas é um íon (cátion ou ânion); e (ii) nas reações vivas a etapa de terminação é suprimida ou significativamente inibida. Desta forma, a espécie ativa responsável pela propagação da cadeia (carbocátion ou carbânion) continua presente no meio reacional até que se esgote o monômero, obtendo-se ao final do processo um polímero vivo; se mais monômero for adicionado ao meio reacional, a reação polimerização é reiniciada ${ }^{[3,14]}$, sem a necessidade de gerar novas espécies ativas. Idealmente, em um processo de polimerização viva, todas as cadeias são iniciadas no início da reação e todas as cadeias crescem simultaneamente com a mesma velocidade média de propagação ${ }^{[7]}$.

Uma das grandes inovações das técnicas de polimerização iônicas, principalmente as aniônicas, foi a introdução da possibilidade da síntese de copolímeros com diversas arquitetura (como bloco, multi-blocos, estrela, dentre outras) e/ou com baixo índice de polidispersão $\left(M_{w} / M_{n}<1.1\right)$. Entretanto, a grande desvantagem das polimerizações iônicas está relacionada às condições reacionais, uma vez que estes sistemas de reação são extremamente sensíveis aos componentes químicos, à presença de impurezas e a mudanças nas condições reacionais, além de serem compatíveis apenas com uma limitada gama de monômeros e solventes ${ }^{[3]}$. Esses fatores limitam a implementação das técnicas de polimerização iônicas em ambientes industriais, além de resultarem em elevados custos operacionais para manter o ambiente reacional suficientemente "limpo" e as espécies propagadoras de cadeia (centro ativo) estáveis ao final da reação de polimerização.

Com o intuito de obter polímeros com arquitetura complexa a baixo custo e utilizando monômeros convencionais (como, por exemplo, estireno, metacrilato de metila e acetato de vinila), uma nova classe de técnicas de polimerização surgiu nos últimos

\section{0}

Copolímero de bloco tipo A-B

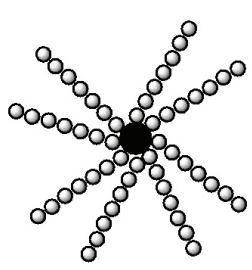

Copolímero estrela

\section{0}

Copolímero de bloco tipo A-B-A

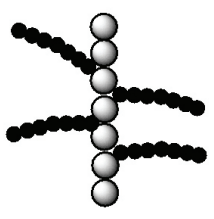

Copolímero de enxerto

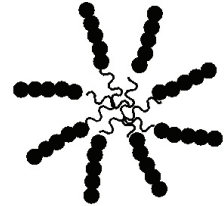

Microgel

Figura 1. Exemplificação de polímeros com arquitetura complexa. Figura adaptada de Moad et al. ${ }^{[7]}$. 
anos: as polimerizações via radicais livres viva/ controlada (Controlled/Living Radical Polymerization, CLRP) ${ }^{[13]}$. Essas técnicas são caracterizadas por abranger simultaneamente as principais vantagens das técnicas de polimerização radicalares e iônicas, sendo possível sintetizar polímeros com arquitetura definida utilizando monômeros e condições reacionais convencionai ${ }^{[13,15]}$.

$\mathrm{O}$ que garante o controle das reações do tipo CLRP é o fato dessas reações, que ocorrem via mecanismo de radicais livres, exibirem características de uma polimerização viva; ou seja, as reações de terminação e outras reações secundárias, que ocasionam a morte da espécie propagadora, são mantidas em níveis reduzidos $^{[15]}$. Embora haja um bom controle da estrutura da cadeia sintetizada, é importante enfatizar que as técnicas de CLRP não são de fato reações vivas. Isso se deve a dois aspectos importantes: nas reações CLRP, a etapa de terminação (principalmente as terminações bimoleculares; Equação 4) não é completamente suprimida e o centro ativo não é constituído por um íon, mas por um radical livre. Entretanto, a grande diferença em relação às reações vivas iônicas é o fato das técnicas CLRP abrangerem vantagens das técnicas radicalares convencionais, como a compatibilidade com uma larga gama de monômeros, grupos funcionais e condições reacionais ${ }^{[13,15]}$, tornando essas técnicas bastante versáteis e mais flexíveis para a obtenção de polímeros com arquitetura definida.

Como qualquer técnica de polimerização via radicais livres, as técnicas de CLRP também estão baseadas em mecanismos que apresentam normalmente três etapas cinéticas: Iniciação, Propagação e Terminação. Entretanto, o que diferencia as técnicas de CLRP da polimerização via radicais livres convencional é a etapa de Propagação, já que as cadeias em crescimento são reversivelmente desativadas, alternando estados ativos e dormentes, ocorrendo o crescimento da cadeias apenas quando estas se encontram no estado ativo, conforme genericamente ilustrado pela Figura $2^{[7,13]}$. Outra grande diferença entre as técnicas de polimerização via radicais livres convencional e as técnicas CLRP é o fato de que as reações de terminação bimoleculares (Equação 4) terem um efeito mais pronunciado sobre controle da massa molar (e também sobre a distribuição de massas molares) apenas nas reações convencionai ${ }^{[13]}$.

Conforme mostrado na Figura 2, diferentes espécies (A) podem ser usadas para provocar a dormência das espécies ativas em crescimento, gerando desta maneira diferentes técnicas de CLRP. Por provocarem um estado de dormência da cadeia em crescimento, muitas vezes essas espécies que estabilizam as cadeias vivas são identificadas como retardadores das reações

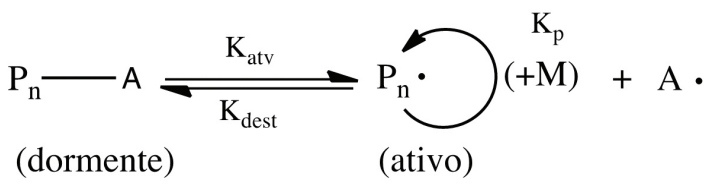

Figura 2. Representação genérica de equilíbrio ativo-dormente em sistemas de CLRP, onde "A" representa o agente de transferência de cadeia (ATC) ${ }^{[13]}$. de polimerização, fato este comprovado pela redução das taxas de consumo de monômero. A condição de equilíbrio e o índice de polidispersão do produto final são afetados pela geração continuada de radicais livres, de maneira que é comum utilizar iniciadores com baixo tempo de meia-vida para iniciar as polimerizações. Além disso, para garantir que o equilíbrio está deslocado no sentido das espécies dormentes, é comum adicionar um certo excesso de agente de transferência de cadeia nesses sistemas de reação.

Embora diversas técnicas de CLRP tenham sido reportadas nas últimas décadas ${ }^{[13]}$, as mais conhecidas e pesquisadas são a Polimerização Mediada por Nitróxido (Nitroxide Mediated Polymerization, NMP), Polimerização Radicalar por Transferência de Átomos (Atom Transfer Radical Polymerization, ATRP) e Transferência Reversível de Cadeia por AdiçãoFragmentação (Reversible Addition-Fragmentation Chain Transfer, RAFT) $)^{[7,13]}$. Dentre os diversos tipos de CLRP, a técnica RAFT é tida como uma das mais versáteis $^{[15-17]}$, podendo ser usada em diversos sistemas e condições reacionais, permitindo a síntese de polímeros com arquitetura definida e estreitas distribuições de massas molares ${ }^{[15,18]}$.

É importante enfatizar alguns conceitos que têm sido difundidos de maneira equivocada na literatura científica. Conforme revisado por Zetterlund et al. ${ }^{[13]}$ o termo vivo deve ser usado unicamente para descrever mecanismos em que cadeias poliméricas podem ter seu tamanho estendido quando mais monômero for adicionado ao meio reacional. Desta forma, as técnicas CLRP não são verdadeiramente técnicas de polimerização vivas, pois para que ocorra a extensão do tamanho da cadeia, além de monômero, deve haver radicais livres presentes no meio reacional. Outro conceito que tem se difundido de maneira equivocada é o termo controle. Este termo só deve ser usado quando a massa molar numérica média $\left(M_{n}\right)$ cresce linearmente e o índice de polidispersão $\left(M_{w} / M_{n}\right)$ decresce, ambos em relação ao aumento da conversão de monômero ${ }^{[13,19]}$. Desta forma, "controle" e "vivo" são características que nem sempre estão associadas, uma vez que, embora seja possível obter copolímeros em bloco usando as técnicas de CLRP, nem sempre esses polímeros são sintetizados de uma forma controlada.

Ainda segundo Zetterlund et al. ${ }^{[13]}$ é um erro associar o sucesso de uma reação de CLRP ao equilíbrio das espécies ativas e dormentes, ocasionando baixas concentrações das espécies ativas em crescimento e consequentemente baixas taxas de terminação. Isso se dá pelo fato de que uma redução nas espécies ativas em crescimento não necessariamente resulta em uma menor taxa de terminação em relação à taxa de propagação. $\mathrm{O}$ ponto fundamental que deve ser observado é que, como nestes sistemas de CLRP o número de cadeias é muito maior, a taxa de terminação por cadeia é consideravelmente menor.

Em muitos casos, seja em ambientes industriais ou em escala laboratorial, é desejável conduzir as reações de polimerização de forma a obter altos rendimentos e polímeros com alta massa molar. Dessa forma, para alcançar esses objetivos, as reações de polimerização 
são preferencialmente conduzidas em sistemas dispersos (ex. emulsão, suspensão, dispersão), o que garante, além de altos rendimentos, fácil recuperação do produto ao final do processo e a possibilidade de obter polímeros com alta massa molar, na forma de partículas sólidas e em alguns casos com morfologia bem definida ${ }^{[20]}$. As técnicas de polimerização via radicais livres, incluindo as técnicas de CLRP, já foram adaptadas para os mais diversos tipos de sistemas dispersos ${ }^{[13]}$. Embora a técnica de polimerização RAFT seja bastante investigada em sistemas em solução ${ }^{[7-10]}$, neste trabalho, é apresentada uma revisão da técnica de polimerização RAFT, focando principalmente os estudos realizados em miniemulsão, uma vez que esse sistema é bastante usado para a obtenção de nanopartículas e nanocápsulas poliméricas com tamanhos inferiores a $500 \mathrm{~nm}$. Esta revisão ainda destaca o uso da técnica de polimerização RAFT em miniemulsão para a síntese desses nano-dispositivos poliméricas para aplicações biotecnológicas.

\section{A Técnica de Polimerização RAFT}

As técnicas de polimerização RAFT ${ }^{[18]}$ e a técnica de polimerização MADIX (Macromolecular Design via the Interchange of Xanthates $)^{[21]}$ foram reportadas na literatura científica quase que simultaneamente. Ambas as técnicas utilizam o mesmo tipo de mecanismo (via radicais livres), divergindo apenas em relação ao tipo de agente de transferência de cadeia utilizado na polimerização. Desta maneira, por conveniência, os agentes de transferência de cadeia RAFT e MADIX são reportados usualmente apenas como agentes RAFT ${ }^{[15]}$.

Conforme descrito por Moad et al. ${ }^{[7]}$ idealmente, as reações de polimerização RAFT podem ser realizadas adicionando-se uma certa quantidade de agente RAFT a uma reação de polimerização convencional, não sendo necessário trocar nenhum componente químico da receita de polimerização (como, por exemplo, o monômero, o iniciador ou o solvente) e nem mesmo adaptar as condições operacionais do sistema (como a temperatura, a pressão e o $\mathrm{pH}$, dentre outros). Como uma técnica de CLRP, a polimerização RAFT permite pré-determinar a massa molar numérica média das cadeias, sintetizar polímeros com estreita polidispersão $\left(M_{w} / M_{n}<1,1\right)$, sintetizar moléculas com arquitetura complexa (conforme ilustrado na Figura 1), entre outras vantagens ${ }^{[7-10]}$

Os agentes RAFT (Figura 3) são compostos químicos que possuem uma função tiocarbonila $(\mathrm{ZC}(=\mathrm{S}) \mathrm{SR})$ ligada a dois grupos distintos, normalmente representados como sendo um grupo "Z" e grupo um "R". Esses grupos possuem funções específicas e a escolha desses grupos exerce influência direta sobre o nível de controle da polimerização. O grupo " $Z$ " possui a função de ativar a dupla ligação $\mathrm{C}=\mathrm{S}$, para favorecer a adição de radicais nesta parte de molécula e proporcionar altas constantes de transferência de fragmentos. Já o grupo "R" deve ser um bom grupo de saída e re-iniciador de reações de radicais livres $^{[7,15,18]}$. Desde as primeiras comunicações sobre a técnica RAFT e MADIX, ${ }^{[18,21]}$ diversos agentes RAFT vêm sendo reportados e classificados de acordo com os tipos de grupos substituintes "Z" e "R". A Figura 3 traz apenas alguns dos inúmeros tipos de grupos " $Z$ " e " $R$ " usados para sintetizar os diversos tipos de agentes RAFT reportados na literatura ${ }^{[7-10]}$.

A escolha do agentes RAFT depende principalmente do(s) monômero(s) a ser(em) polimerizado(s) de forma controlada, o que remonta diretamente à estrutura do agente RAFT, principalmente de seus grupos substituintes "R" e "Z". As principais revisões sobre o tema normalmente trazem um guia para a seleção do agente RAFT mais adequado em função do monômero (ou comonômeros) escolhidos, levando em consideração a reatividade de adição e fragmentação dos grupos " $Z$ " e "R" $\mathrm{R}$ [7-10,15].

O mecanismo pelo qual ocorre a polimerização RAFT geralmente é descrito em termos de cinco etapas ${ }^{[7-10,15,16,22]}$, compreendendo as etapas de Iniciação, Transferência reversível de cadeia, Re-iniciação, Equilíbrio de cadeia e Terminação. A etapa Iniciação ocorre exatamente como numa reação via radicais livres convencional, em que são gerados os radicais livres que dão início à reação de polimerização (Equações 1 e 2). Embora seja possível usar diferentes métodos para gerar os radicais livres, os quais incluem o uso estimulação fotoquímica (por radiação UV, laser e radiação- $\gamma$ ), a decomposição térmica de iniciadores químicos é o método mais adotado para gerar os radicais livres em polimerizações RAFT ${ }^{[15]}$.<smiles>[R]SC(=S)c1ccccc1</smiles>

Ditiobenzoato<smiles>[R]SC(=S)N([Z2])[Z]</smiles>

Ditiocarbamato<smiles>[R]SC(=S)S[Z]</smiles>

Tritiocarbonato<smiles>[R]SC(=S)O[3H]</smiles>

Xantatos (MADIX)
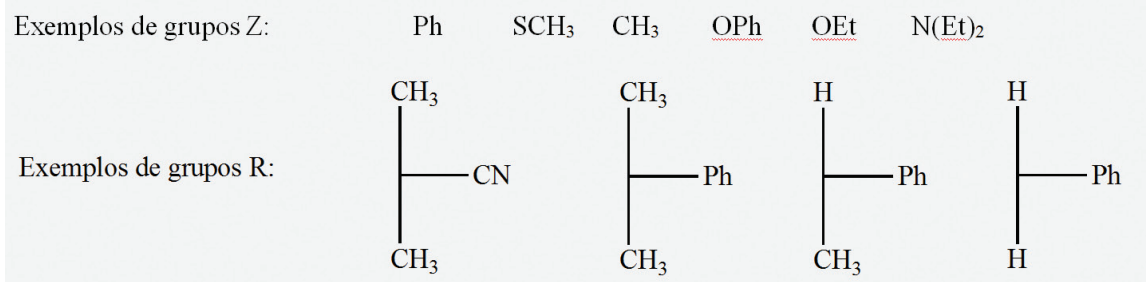

Figura 3. Principais tipos de agentes RAFT e alguns exemplos de possíveis grupos substituintes "Z" e "R"[7-10]. 
Em seguida, na etapa de Transferência reversível de cadeia (Equação 6), pequenas espécies em crescimento oriundas da etapa de iniciação reagem preferencialmente com as moléculas de agente RAFT presentes no meio reacional, devido à alta reatividade da ligação $\mathrm{C}=\mathrm{S}$ do agente RAFT frente a qualquer outro tipo de insaturação presente no meio reacional, como por exemplo as duplas ligações dos monômeros vinílicos. $\mathrm{O}$ agente
RAFT pode então retornar à configuração original ou "liberar" o fragmento $R \bullet$, que participa da etapa de Re-iniciação (Equação 7), gerando cadeias poliméricas em crescimento.

Na etapa de Equilíbrio de cadeia (Equação 8), acontece um equilíbrio dinâmico entre estágios ativos e dormentes das cadeias poliméricas, apenas ocorrendo o crescimento das cadeias quando estas se encontram no estado ativo.

Transferência reversível de cadeia

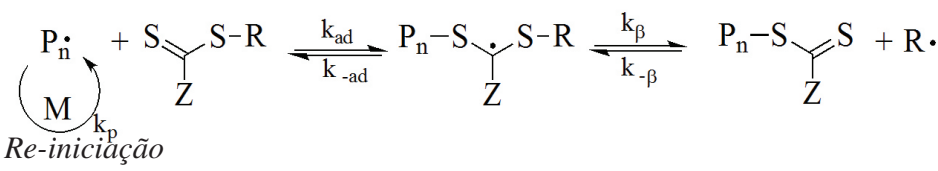

$$
\mathrm{R} \cdot+\mathrm{M} \stackrel{\mathrm{k}_{\mathrm{p}}}{\rightleftharpoons} \mathrm{P}_{\mathrm{m}}
$$

\section{Equilíbrio de cadeia}

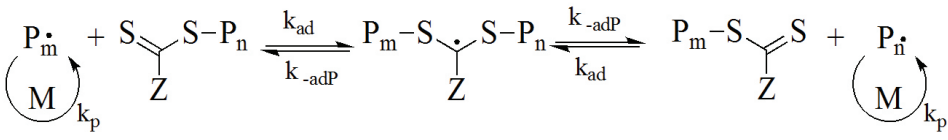

A principal diferença da técnica RAFT para a reação via radicais livres convencional é que na reação RAFT as cadeias em crescimento são rapidamente capturadas pelo grupo tiocarbonila do agente RAFT. Isto ocasiona o intercâmbio das cadeias em crescimento com o agente RAFT, garantindo que todas as cadeias tenham a mesma chance de crescer. A última etapa do processo, embora minimizada, compreende as reações de Terminação, em que são geradas cadeias de polímeros mortas. Quando uma reação de polimerização RAFT é bem executada, as terminações bimoleculres são mantidas em níveis negligenciáveis, o que acarreta na formação majoritariamente de cadeias poliméricas "dormentes"; ou seja, cadeias poliméricas ligadas a uma molécula de agente RAFT cada. Desta forma, o polímero "dormente" pode ser reutilizado em outras etapas do processo de polimerização, obtendo-se polímeros com diversas arquiteturas. Entretanto, conforme já mencionado, ao contrário das reações de polimerização viva, para que ocorra a extensão da cadeia polimérica com comonômero(s), pode ser necessária novamente a geração de radicais livres no meio, além da presença do(s) comonômero(s) de interesse.

Como em todas as técnicas de CLRP, o sucesso da técnica de polimerização RAFT geralmente é determinada pelo nível de controle exercido sobre a evolução da reação de polimerização. Na prática, isso se traduz no crescimento linear da massa molar numérica média $\left(M_{n}\right)$ com a conversão, na diminuição do índice de polidispersão $\left(M_{w} / M_{n}\right)$ (Figura 4$)$ e no deslocamento das distribuições de massas molares com a conversão (Figura 5).

Com a inserção do grupamento tiocarbonila do agente RAFT na cadeia polimérica, este possibilita a formação de diversas arquiteturas, como a formação de blocos de copolímeros (Figura 6). Os copolímeros do tipo di-bloco são bastante sintetizados via polimerização RAFT. Eles são
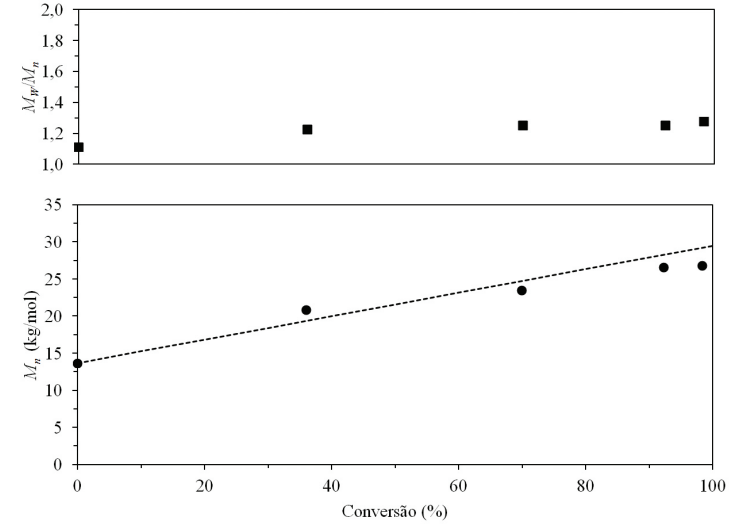

Figura 4. Evolução do índice de polidispersão $\left(M_{w} / M_{n}\right)$ e massa molar numérica média $\left(M_{n}\right)$ em função da conversão da polimerização do 2-(dimetilamino) metacrilato de etila na presença de agente macro-RAFT em miniemulsão inversa. A linha pontilhada representa o valor teórico de $M_{n}^{[6,23]}$.

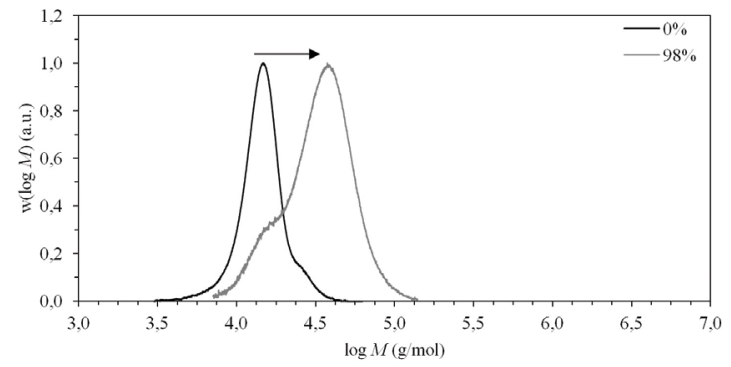

Figura 5. Evolução da distribuição da massa molar em função da conversão da polimerização do 2-(dimetilamino) metacrilato de etila na presença de agente macro-RAFT em miniemulsão inversa $^{[6,23]}$. 
formados por intermédio de reações de extensão de cadeia, em que inicialmente ocorre uma homopolimerização na presença de um agente RAFT, formando um polímero que contém um grupo tiocarbonila terminal, normalmente conhecido como macro-RAFT. A formação do di-bloco ocorre com uma nova homopolimerização, porém na presença de outro monômero e do macro-RAFT, além de radicais livres para iniciar a polimerização ${ }^{[16]}$. Virtualmente, a cadeia pode ter seu tamanho estendida infinitas vezes, com a formação de multi-blocos de copolímeros, à medida que o grupamento tiocarbonila do agente RAFT for preservado no polímero final obtido.

Um ponto bem explorado, é a possibilidade de calcular a massa molar numérica média teórica $\left(M_{n, t h}\right)$ do polímero a ser sintetizado como função da conversão do monômero $(\alpha)$ e das condições reacionais ${ }^{[7]}$. Nesse cálculo (Equação 9), evidencia-se que a proporção entre o monômero e o agente RAFT é um dos pontos fundamentais para a obtenção de polímeros com alta massa molar. Os valores de massa molar teórica geralmente são usados como um guia para avaliar o controle da reação, em função de resultados de massa molar experimentais (Figura 4). Além disso, a possibilidade de calcular a massa molar do polímero permite desenhar polímeros com arquitetura complexa de forma mais precisa. É importante frisar que as massas molares médias obtidas pela técnica RAFT estão associados à concentração de agente RAFT usado nas reações. Por isso, e como esses agentes são naturalmente retardadores da reação de polimerização via radicais livres, os valores globais de massa molar geralmente obtidos não ultrapassam $10^{5} \mathrm{~g} / \mathrm{mol}$.

$$
M_{n, t h}=\left(\frac{[M]_{0}}{[R A F T]_{0}} \times M w_{\text {monômero }} \times \alpha\right)+M w_{R A F T}
$$

Em relação às condições experimentais, a técnica RAFT pode ser conduzida em condições bem similares às das reações via radicais livres convencionais. Conforme descrito anteriormente, diversos métodos podem ser usados para gerar radicais livres, embora a decomposição térmica de iniciadores químicos constitua o método mais adotado para gerar os radicais livres em polimerizações RAFT ${ }^{[15]}$, o que inclui o uso dos mesmos tipos de iniciadores usados em reações via radicais livres (azo-compostos, peróxidos, persulfatos, etc. $)^{[16]}$. Em relação à concentração de iniciador, idealmente a relação molar de agente RAFT para a quantidade iniciador decomposto deve ser de 10:1 aproximadamente. Entretanto, em muitos casos usam-se maiores concentrações de iniciador, com o intuito de obter taxas de reação mais adequadas e também evitar perdas de iniciador devido à presença de impurezas e/ou altas concentrações de oxigênio ${ }^{[10]}$.

Embora as reações de polimerização via radicais livres sejam sensíveis à presença de oxigênio, o real papel da presença de oxigênio no meio reacional e sua associação com efeitos de inibição/retardamento das taxas de reação devem ser estudadas caso-a-caso. Para as reações RAFT, é comum adotar práticas para reduzir a presença de oxigênio no meio reacional, principalmente em sistemas de polimerização em solução. Entretanto, em alguns casos foi reportado que a presença de oxigênio parece não exercer nenhum efeito na taxa reacional da polimerização RAFT ${ }^{[16]}$.

Em relação à temperatura de polimerização, conforme revisado por Moad et al. ${ }^{[10]}$ já foram reportadas reações de polimerização RAFT bem sucedidas em diversas temperaturas, variando de valores inferiores à temperatura ambiente até $140{ }^{\circ} \mathrm{C}$. Segundo os autores, o efeito da temperatura se torna importante, uma vez que reações conduzidas a baixas temperaturas podem estar sujeitas a efeitos retardantes mais expressivos, ao passo que altas temperaturas podem ocasionar uma completa degradação do agente RAFT. Além do efeito da temperatura, a degradação do agente RAFT está diretamente associada à compatibilidade com os outros componentes químicos e o $\mathrm{pH}$ do meio reacional. Um exemplo é a degradação por hidrólise dos agentes RAFT, normalmente mais pronunciada em altas temperaturas e pH básico (7,5-8,5). Diversos agentes RAFT também mostram são incompatíveis com a presença de aminas primárias e secundárias, que levam à degradação do agente RAFT por aminólise ${ }^{[16]}$.

Desde a sua descrição, feita há mais de dez anos na literatura científica ${ }^{[18]}$, a técnica de polimerização RAFT tem despertado interesse de alguns pesquisadores brasileiros, que dedicaram esforços para explorar essa nova técnica de polimerização. A primeira publicação sobre a técnica de polimerização RAFT envolvendo pesquisadores brasileiros foi publicada em $2006^{[24]}$, embora esta tenha sido uma pesquisa mais voltada para a área de simulação. Porém, somente em $2007^{[25]}$ é que foram publicadas de fato as primeiras pesquisas experimentais envolvendo pesquisadores brasileiros com o tema. Outros artigos sobre polimerização RAFT, envolvendo a participação de pesquisadores brasileiros, vêm sendo publicados até a presente data ${ }^{[23,26-33]}$, sendo algumas dessas totalmente desenvolvidas em universidades brasileiras ${ }^{[29,31-33]}$. O tema da polimerização RAFT também já foi abordado recentemente, de forma resumida, em outras publicações nacionais ${ }^{[27]}$. No entanto, embora nos últimos anos alguns pesquisadores tenham dedicados esforços para utilizar e investigar alguns aspectos da técnica de polimerização RAFT, a contribuição brasileira ainda é muito pequena se comparada ao grande número de publicações sobre o tema nos periódicos internacionais.

\section{Polimerização RAFT em Miniemulsão}

A polimerização RAFT ainda pode ser considerada uma técnica recente da Ciência de Polímeros, já que o primeiro estudo foi publicado por Chiefari et al. em $1998^{[18]}$. Contudo, em seguida a técnica RAFT começou

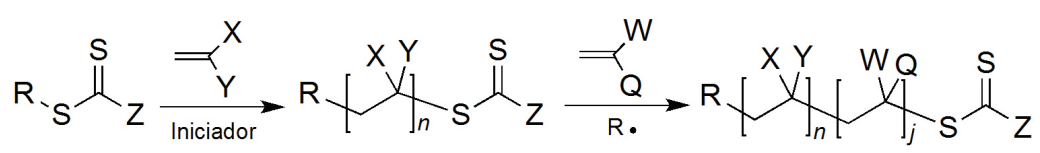

Figura 6. Exemplificação da formação de blocos de copolímero via extensão de cadeia utilizando a técnica de polimerização RAFT ${ }^{[16]}$. 
a ser implementada em diversos sistemas homogêneos e heterogêneos de polimerização ${ }^{[7-10]}$, o que incluiu as emulsões, suspensões e dispersões ${ }^{[13]}$, além das primeiras comunicações relacionadas à polimerização RAFT em miniemulsão ${ }^{[34,35]}$.

As emulsões poliméricas constituem de longe os sistemas dispersos mais bem estudados na área de polímeros. Convencionalmente, um sistema normal/direto de emulsão descreve a dispersão de um ou mais monômeros de natureza lipofílica (como estireno) em um fase contínua polar, que normalmente é a água. No sistema inverso, o monômero usado possui caráter hidrofílico (como acrilamida), o que requer o uso de uma fase contínua de caráter apolar (como hexano). Independentemente do sistema ser direto ou inverso, surfactantes são empregados para diminuir a tensão interfacial entre a fases dispersa e contínua, contribuindo para gerar a emulsão e aumentar a estabilidade do sistema. O termo latex normalmente é empregado para designar o produto de um processo de polimerização em emulsão, que é uma dispersão coloidal de partículas poliméricas em água ${ }^{[36]}$.

Os sistemas em emulsão podem ser divididos basicamente em três principais tipos: macro-emulsão, mini-emulsão e a micro-emulsão. Embora os diferentes tipos de emulsões poliméricas gerem ao final do processo de polimerização partículas com tamanhos característicos, esses sistemas não são definidos principalmente pela faixa de gota/partícula gerado ao longo do processo, mas sim pelo mecanismo envolvido na formação dessas gotas/ partículas $^{[37]}$.

As macro-emulsões, comumente conhecidas apenas como emulsões poliméricas, possuem um mecanismo de reação bastante particular ${ }^{[38-42]}$. Neste sistema, o processo de emulsificação gera inicialmente gotas de monômero de tamanho micrométrico, que, estabilizadas por surfactantes, funcionam como um reservatório de monômero do sistema. À medida que a reação de polimerização avança, o monômero difunde através da fase contínua até chegar a uma micela, formada pelo excesso de surfactante presente no meio, onde de fato ocorre a reação de polimerização. Ao final do processo de polimerização, todas as gotas de monômeros foram consumidas e o produto final é constituído de um látex com tamanho médio das partículas normalmente maiores que $100 \mathrm{~nm}^{[37]}$.

As micro-emulsões são sistemas geralmente formados pela mistura de grandes quantidades de surfactantes, o que implica na falta de necessidade de usar alta energia de cisalhamento para formar a emulsão. As gotas apresentam uma cobertura completa de sua superfície por emulsificante, sendo que a polimerização ocorre por mecanismos de nucleação primária e secundária, gerando ao final do processo um látex composto por micelas e partículas com diâmetro médio em torno de 5-50 $\mathrm{nm}^{[37]}$.

As mini-emulsões apresentam um mecanismo completamente diferente de formação das partículas poliméricas. Neste sistema, o processo de emulsificação gera gotas na faixa de 50-500 nm e com uma distribuição de tamanhos bastante homogênea. Uma vez que a concentração de surfactante nas miniemulsões está abaixo da concentração micelar crítica $(\mathrm{CMC})$, não há micelas presentes no sistema. Dessa forma, no sistema em miniemulsão a reação de polimerização ocorre dentro das gotas de monômeros, que funcionam como uma espécie de "nano-reator". Se um processo de polimerização em miniemulsão for bem controlado, o látex polimérico obtido é basicamente uma "cópia" das gotas originalmente formadas no processo de emulsificação, sendo a distribuição final do tamanho de partículas definida por um conjunto de variáveis, que incluem principalmente a concentração de surfactante, o processo de geração da miniemulsão e a estabilidade do sistema ao longo da reação de polimerização ${ }^{[37,43,44]}$.

Uma vez que as miniemulsões formam sistemas termodinamicamente instáveis, para formar a emulsão é necessário o emprego de uma força de cisalhamento de alta energia que consiga "quebrar" a fase dispersa em gotas nanométricas e com uma faixa de distribuição de tamanhos estreita. Embora diversos processos possam ser empregados, o uso de ultrassom e homogeneizadores de alta pressão são as técnicas/equipamentos mais empregadas $^{[45]}$. Embora a utilização de equipamentos que empregam uma força de cisalhamento de alta energia constitua o método mais usado para gerar miniemulsões, alternativas que utilizam baixa energia também já foram reportados ${ }^{[46-48]}$. Isso inclui um recente trabalho publicado por Zetterlund et al. ${ }^{[49]}$ sobre o controle de tamanho de partículas de poliestireno obtidas por polimerização RAFT em miniemulsão utilizando $\mathrm{CO}_{2}$ pressurizado, ao invés dos métodos tradicionais de alta energia para gerar a miniemulsão.

As miniemulsões diretas são sistemas constituídos basicamente por uma dispersão de surfactantes hidrossolúveis em água, que estabilizam gotas hidrofóbicas de tamanho entre 50-500 $\mathrm{nm}^{[50,51]}$. Como em qualquer sistema heterogêneo, existem pelo menos duas fases: uma fase contínua e uma fase dispersa. A fase contínua normalmente representa a maior fração do sistema (tipicamente de 50 a $90 \%$ do volume total), sendo constituída por um líquido dispersante de caráter polar (nos sistemas diretos) ou apolar (nos sistemas inversos). A fase dispersa da miniemulsão é constituída principalmente pelo monômero ou mistura de comonômeros, que podem ser de caráter organossolúvel (como metacrilato de metila), para os sistemas diretos, ou então hidrossolúvel (como o ácido acrílico), no caso de miniemulsão inversa ${ }^{[51]}$.

De forma resumida, as principais características que um sistema deve apresentar para ser considerado uma miniemulsão polimérica ${ }^{[37,44,51]}$ incluem:

- Durante o processo de emulsificação, que normalmente requer o emprego de altas energias de cisalhamento, o tamanho final das gotas é definido por um processo dinâmico de fissão e coalescência, que tende a atingir a um estado de equilíbrio dinâmico;

- O uso de um agente de pressão osmótica* garante a estabilidade das gotas após o processo de emulsificação. Quando todas as gotas possuem a mesma pressão interna efetiva, o tamanho das gotas

\footnotetext{
* Agente de pressão osmótica - substância usada para equilibrar a pressão osmótica no interior das gotas, e com isso, evitar efeitos de degradação difusional. Devem apresentar pouca solubilidade na fase contínua do sistema $\left(<10^{-7} \mathrm{mg} / \mathrm{mL}\right)$. Os agentes de pressão osmótica são erroneamente denominados "co-surfactantes", uma vez que a grande maioria das substâncias não possui qualquer similaridade química com os surfactantes ${ }^{[50,51]}$.
} 
não se altera por efeitos de degradação difusional (Ostwald ripening), mas apenas por colisão das gotas;

- A polimerização em miniemulsões só ocorre por intermédio da etapa de nucleação das gotas;

- Em um sistema de miniemulsão, uma vez que a quantidade de surfactante está abaixo da CMC, a cobertura das gotas pelo surfactante é quase sempre incompleta, o que evita a formação de micelas e o mecanismo de nucleação micelar;

- O tamanho final das gotas está diretamente relacionado à quantidade de surfactante. Quanto maior for a concentração de surfactante no meio, menor será o tamanho das gotas (e maior a cobertura das gotas com surfactante);

- Nos sistemas em miniemulsão, a polimerização pode ser iniciada por diversas maneiras, o que inclui o uso de iniciadores químicos na fase dispersa, contínua e/ ou interface do sistema.

- Em sistemas inversos, a existência de uma interface compacta de surfactantes pode ajudar a estabilizar as gotas. Entretanto, essa interface pode constituir uma barreira intransponível à entrada de radicais, caso esses sejam gerados na fase contínua do sistema.

De modo comparativo a outros sistemas dispersos de polimerização, as miniemulsões podem ser "grosseiramente" comparadas às suspensões poliméricas, uma vez que em ambos os sistemas os loci das reações de polimerização são as gotas monoméricas dispersas no sistema. Porém, esses sistemas apresentem diversas diferenças fundamentais, sendo possível identificar o tamanho das gotas/partículas formadas, o processo de estabilização das partículas e o processo de formação das gotas como algumas das principais diferenças entre os dois sistemas de polimerização ${ }^{[37]}$.

Ao contrário dos outros sistemas dispersos, a geração de radicais na miniemulsão pode ocorrer na fase dispersa, na fase contínua, na interface entre as fases ou em mais de uma fase, quando mais de um iniciador é usado ${ }^{[44]}$. Mesmo que a geração de radicais ocorra, por exemplo, na fase contínua da miniemulsão, as reações de polimerização ocorrem predominantemente nas gotas dispersas por meio do mecanismo de nucleação das $\operatorname{gotas}^{[37]}$. De acordo com esse mecanismo, as gotas formadas durante o processo de emulsificação são nucleadas pela entrada de radicais, que são gerados na fase contínua do sistema. Idealmente, admite-se que o processo de nucleação das gotas, pela entrada de radicais gerados na fase contínua do sistema, é o mecanismo dominante de nucleação do sistema e que todas as gotas do sistema são nucleadas. Isso implica que, desconsiderando os processos de coalescência e/ou degradação difusiva ${ }^{[45]}$, o número de gotas/partículas poliméricas não se altera durante a reação de polimerização.

Entretanto, uma característica vantajosa dos sistemas em miniemulsão é a possibilidade da geração de radicais ocorrer diretamente no interior da gota monomérica. Uma vez que iniciadores químicos são largamente utilizados para gerar radicais livres nesses sistemas, pode ser feita a escolha de iniciadores solúveis no monômero. Dessa forma, quando a fase dispersa é emulsificada, garante-se que todas as gotas serão nucleadas, pois teoricamente todas as gotas terão uma fração de iniciador dissolvida em seu interior.
A escolha do tipo de geração de radicais exerce influência direta sobre o controle da reação em sistemas em miniemulsão, sendo necessário um estudo caso-a-caso de cada sistema. Como exemplo, Schork et al. ${ }^{[52]}$ reportaram que a geração de radicais diretamente no interior das gotas possibilitou um melhor controle da polimerização RAFT de acrilamida em miniemulsão inversa. Entretanto, em alguns sistemas de miniemulsão, o controle da reação é favorecido quando a geração dos radicais ocorre apenas na fase contínua do sistema, uma vez que alguns tipos de iniciadores apresentam mecanismos complexos de partição entre as diferentes fases da miniemulsão, levando a controle menos preciso das condições de reação ${ }^{[51]}$.

A Tabela 1 apresenta os estudos publicados até a presente data sobre a produção de polímeros que utilizaram a técnica RAFT em miniemulsão. Conforme revisado, a técnica de polimerização RAFT em miniemulsão já foi adaptada para os principais tipos de monômeros comerciais (como, por exemplo, estireno ${ }^{[28,34,35,53-73]}$, metacrilato de metila [35,54,68,74-80]), sistemas inversos ${ }^{[23,52,81-86]}$ e sistemas contínuos de polimerização ${ }^{[87-89]}$ ). Além dos trabalhos citados na

Tabela 1. Exemplos de polímeros obtidos via polimerização RAFT em miniemulsão.

\begin{tabular}{lccc}
\multicolumn{1}{c}{ Polímero $^{\mathrm{a}}$} & Sistema & Nota & Referência \\
\hline PSt $^{\mathrm{b}}$ & & & {$[28,34,35$,} \\
& & & $53-73]$ \\
& Direto & CSTR & {$[88,89]$} \\
& & Tubular & {$[98-100]$} \\
PMMA & Direto & & {$[35,54,68,74-80]$} \\
PnBMA ${ }^{\mathrm{c}}$ e & & & {$[35,53,101-106]$} \\
copolímeros em bloco & - & & {$[35,53]$} \\
PEHMA & Direto & & {$[107-109]$} \\
PnBA & Direto & & {$[110-112]$} \\
PVAc & Direto & & {$[52,81,83-85]$} \\
PAM & Inverso & & {$[85]$} \\
PAA & Inverso & & {$[54,113-120]$} \\
Copolímeros em & & & {$[97]$} \\
bloco com PSt & Direto & CSTR & \\
& & Tubular &
\end{tabular}

Copolímeros em

bloco com PMMA

Direto

$[35,121,122]$

Polímeros e

Copolímero

glicosilados

Copolímeros

em bloco com

PDMAEMA

P(MAA-co-DFHA)/

$\mathrm{P}(\mathrm{DFHA}-\mathrm{co}-\mathrm{DVB})^{\mathrm{c}}$

$\mathrm{P}(\mathrm{AM}-c o-\mathrm{AA})$

Direto

P(NIPAM- $b$-PEO)

Inverso

${ }^{a}$ Poliestireno (PSt), poli(metacrilato de metila) (PMMA), poli(buitl metacrilato (PnBMA), poli(hidroxietil metacrilato) (PEHMA), poli(butil acrilato) (PnBA), poli(acetato de vinila) (PVAc), Poliacrilamida (PAM), poli(ácido acrílico), poli(2-dimetilamino (metacrilato de etila)) (PDMAEMA), ácido metacrílico (MAA), acrilato de dodecafluoro heptil (DFHA), acrilamida (AM), ácido acrílico (AA), isopopil acrilamida (NIPAM), poli(óxido de etileno) (PEO). ${ }^{\mathrm{b} A l g u n s}$ polímeros foram sintetizados a partir de agentes macro-RAFT. 'Inclui experimentos com monômeros fluorados. 
Tabela 1, estudos teóricos sobre a polimerização RAFT em miniemulsão também já foram publicados ${ }^{[90-97]}$, contribuindo com a melhor compreensão sobre a cinética de polimerização (e outras características) desse sistema.

De forma geral, a Tabela 1 mostra que a polimerização RAFT pode ser conduzida em miniemulsão de forma bem sucedida, embora a redução significativa das taxas de polimerização e das massas molares médias do produto final não incentive a produção industrial de commodities por essa técnica. Por isso, a maior parte dos trabalhos trata de aspectos mecanísticos (por exemplo, a estimação de parâmetros cinéticos e de sorção e dessorção dos radicais das gotas emulsificadas, com objetivo de explicar principalmente os bem conhecidos efeitos de compartimentalização das reações conduzidas em miniemulsão) e da produção de especialidades químicas, voltadas majoritariamente para as aplicações biotecnológicas, o que inclui principalmente os sistemas de liberação de fármacos e biomoléculas ${ }^{[23,82,86,123,124]}$. Nesse caso, é lícito dizer que a polimerização RAFT tem sido utilizada principalmente para permitir o controle da composição das cadeias poliméricas formadas (explorando o caráter "vivo" da reação) e permitir a funcionalização posterior das nanopartículas poliméricas (explorando a alta reatividade do grupamento $\mathrm{C}=\mathrm{S}$ dos agentes RAFT normalmente utilizados). Nesse sentido, a técnica RAFT é extremamente vantajosa, quando comparada a outras técnicas de polimerização, pois o resíduo do agente de transferência de cadeia constitui um centro natural para posterior funcionalização das cadeias poliméricas. É curioso perceber que os trabalhos publicados não exploram para fins práticos os baixos índices de polidispersão das cadeias poliméricas produzidas, o que reforça a importância da manipulação das composições para as aplicações reais de interesse. $\mathrm{O}$ interesse reduzido pela distribuição de massas molares, nesse caso, está intimamente relacionado com o uso dos materiais poliméricos nas aplicações biotecnológicas, que em geral privilegiam a forma das partículas produzidas e a composição do material, em detrimento do controle rígido das massas molares médias, que afetam pouco o desempenho do produto final do produto.

\section{Aplicações em biotecnologia}

Em função da discussão apresentada na seção anterior, é conveniente analisar de forma um pouco mais detalhada as aplicações biotecnológicas resultantes das polimerizações RAFT conduzidas em miniemulsão.

Já faz algum tempo que os polímeros sintéticos vêm sendo largamente utilizados em aplicações biotecnológicas $^{[126]}$, incluindo a síntese/produção de compostos para uso em diversas aplicações médicas e farmacêuticas. Em geral, a estratégia de síntese do polímero pode variar de acordo com a aplicação final desejada. Entretanto, para um melhor desempenho biotecnológico, a obtenção de materiais com propriedades uniformes constitui uma meta comumente desejada, incluindo as características de massa molar, arquitetura da cadeia polimérica, composição e funcionalidades químicas. Outro ponto importante diz respeito à conjugação de fármacos/biomoléculas com polímeros, que é uma estratégia muitas vezes adotada para aumentar a atividade farmacológica in vivo dessas substâncias ${ }^{[15,17]}$.

Uma aplicação biotecnológica bastante estudada nos últimos anos é a síntese de nano-hidrogéis poliméricos para uso em aplicações de liberação controlada ${ }^{[127-130]}$. Os nano-hidrogéis são nanopartículas poliméricas hidrofílicas e reticuladas que encontram aplicações biotecnológicas por causa de algumas vantagens, que incluem a possibilidade de controle do tamanho das nanopartículas com relativa precisão pela técnica de miniemulsão, a grande interface disponível para a realização de bioconjugações e o fato de que as nanopartículas podem ser usadas para carrear fármacos hidrofílicos. Além disso, controlando-se a densidade de reticulação dos nanogéis, é possível criar uma matriz com uma porosidade definida, o que permite um controle mais preciso da capacidade do nanogel polimérico de absorver e liberar fármacos (ou biomoléculas) de uma maneira controlada $^{[129]}$. Entretanto, para otimizar o desempenho dos nanogéis em aplicações de liberação controlada, vários critérios devem ser satisfeitos ${ }^{[128]}$, os quais incluem a boa estabilidade durante a circulação in vivo, a presença de grupos funcionais na superfície das nanopartículas (para aumentar o "reconhecimento" do gel por receptores celulares), o tamanho de partícula menor que $200 \mathrm{~nm}$ e a biodegradabilidade por meio de estímulo externo (como o pH e a ação enzimática). A biodegradação do nanogel constitui um fator particularmente importante, pois este influencia diretamente a liberação do composto de interesse, além de facilitar a remoção das nanopartículas "vazias" e seus resíduos ${ }^{[23]}$.

Para sintetizar nano-hidrogéis por meio de polimerizações com reticulação, é quase sempre necessário usar um sistema inverso; ou seja, um sistema em que a fase contínua seja de caráter apolar e a fase dispersa polar, estabilizada por um surfactante lipofílico $^{[13]}$. Quando se deseja carregar as nanopartículas com produtos orgânicos ou inorgânicos, solúveis ou não no meio reacional, o sistema heterogêneo de polimerização mais viável para sintetizar essas nanopartículas híbridas $^{[131-133]}$ é a polimerização em miniemulsão, em função da facilidade para dispersar o meio reacional na presença de outros materiais, solubilizados ou não na carga de monômeros ${ }^{[134,135]}$. Por isso, não surpreende que os nano-hidrogéis sejam produzidos majoritariamente por miniemulsões inversas.

Conforme já revisado, as técnicas de CLRP ${ }^{[136]}$ permite a síntese de polímeros com arquitetura molecular definida, tendo sido recentemente adaptada para uso em diversos tipos de sistemas dispersos de polimerização, o que torna possível o uso de diversas técnicas de CLRP como rota de síntese de nanogéis com arquitetura molecular complexa e definida ${ }^{[13,137-141]}$. De uma forma geral, as técnicas de CLRP em sistemas dispersos são de fato rotas bem atrativas para a síntese de nano-hidrogéis com estrutura molecular bem definida (ex. copolímeros em bloco, multi-blocos etc.), para uso biotecnologia $^{[127-129]}$. Dentre as diversas vantagens de usar técnicas de CLRP para a síntese de nanogéis, inclui-se o fato de que o nanogel formado por cadeias polimérica uniformes $\left(M_{w} / M_{n}<1,3\right)$ garante um melhor perfil de 
degradação/liberação dos componentes encapsulados (ex. fármacos, biomoléculas, etc.), melhorando o desempenho do nanogel como sistema de liberação de fármacos ${ }^{[128]}$. Além disso, o nanogel pode ser formado por blocos mais regulares, no caso de copolimerizações.

Dentre as diversas técnicas de CLRP desenvolvidas até hoje, a técnica RAFT é tida atualmente como a mais versátil[ ${ }^{[16,17]}$. Dessa forma, o uso da técnica de polimerização RAFT oferece inúmeras vantagens para a síntese de polímeros para aplicações biotecnológicas ${ }^{[15,17]}$, dentre as quais podem ser citados quatro principais pontos: (i) a possibilidade do uso de uma grande variedade de monômeros e solventes ${ }^{[7,18]}$; (ii) o uso da técnica RAFT possibilita também a síntese de polímeros com diversos tipos de arquitetura molecular ${ }^{[7,16]}$; (iii) o fato da técnica de polimerização RAFT ter sido adaptada para uso em diferentes sistemas de polimerização ${ }^{[34,142-144]}$, incluindo a miniemulsão direta ${ }^{[34,35]}$ e inversa ${ }^{[52]}$; e (iv) a baixa toxicidade de alguns agentes RAFT empregados nas polimerizações ${ }^{[145,146]}$. Isso possibilita o uso da técnica RAFT na síntese de nanogéis biodegradéveis e com partículas menores que $200 \mathrm{~nm}$, utilizando um sistema de miniemulsão inversa, por exemplo ${ }^{[23]}$.

Além das características anteriormente descritas, uma vantagem única dos polímeros sintetizados via técnica RAFT, é a possibilidade de reação dos grupos terminais das cadeias poliméricas. $\mathrm{O}$ grupo $\mathrm{Z}$ do agente RAFT é pouco estável e susceptível a diversas reações de degradação, principalmente as reações de aminólise ${ }^{[147]}$, hidrólise $^{[148,149]}$, redução radicalar induzida ${ }^{[150]}$, radiação $\mathrm{UV}^{[151]}$ e termólise ${ }^{[148,152]}$. Além disso, reações de aminólise são frequentemente usadas para transformar o grupo tiocarbonila terminal em um grupamento tiol (Figura 7) ${ }^{[15,17,145]}$, que é das funções mais versáteis da química orgânica. A presença de um grupamento tiol nas porções terminais das cadeias poliméricas abre diversas possibilidades de pós-funcionalização e bioconjugação dos polímeros formados com moléculas de interesse, como fármacos, RNA, DNA, peptídeos, dentre outros tipos de biomoléculas. Além disso, a transformação do grupo tiocarbonila em um grupamento tiol está associado à redução da toxicidade de alguns agentes RAFT ${ }^{[145]}$.

Embora a técnica de polimerização RAFT seja bastante atrativa, inclusive para implementação em ambientes industriais, esta técnica também apresenta algumas desvantagens. Em um passado recente, um dos maiores obstáculos para o uso dessa técnica era o acesso aos agentes RAFT. Entretanto, este cenário reverteu-se nos últimos anos, sendo que atualmente alguns agentes RAFT já estão disponíveis comercialmente para fins de pesquisa ${ }^{[17]}$. Entretanto, a maior parte dos agentes RAFT reportados ainda é obtida com auxílio de técnicas de síntese orgânica, com relativo grau de pureza ${ }^{[7-10]}$. Deve-se ressaltar que atualmente não parece haver qualquer polímero produzido comercialmente em grandes

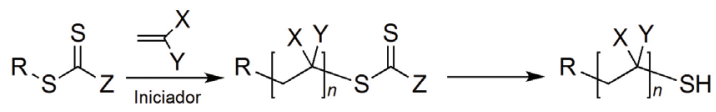

Figura 7. Polimerização RAFT e pós-modificação do grupo tiocarbonila terminal em grupamento tiol ${ }^{[7,15,17]}$. quantidades via polimerização RAFT, principalmente em função do alto custo do agente RAFT (cerca de US\$ 200,00 por grama), que constitui um dos empecilhos para a adaptação desta técnica a escalas industriais, principalmente para a produção de commodities. Entretanto, deve-se lembrar que, dependendo da aplicação final (como em sistemas biomédicos), o alto custo de produção pode ser compensado pela produção em larga escala dos agentes RAFT. Outro aspecto que deve ser observado é a toxicidade do agente RAFT. Embora os diferentes agentes possuam toxicidades distintas, existem diversas estratégias para reduzir a toxicidade associada ao gente RAFT antes de empregar o polímero em aplicações biotecnológicas, como a já citada pós-modificação do grupo tiocarbonila terminal em grupamento tiol ${ }^{[145]}$.

Um aspecto curioso da técnica de polimerização RAFT é que grande parte dos agentes RAFT utilizados possui uma coloração intensa, que varia do roxo ao amarelo. Isso faz com que o polímero final obtido geralmente tenha uma coloração característica, que varia de acordo com a concentração e tipo de agente RAFT utilizado. A obtenção do polímero colorido pode ter algumas vantagens e desvantagens, dependendo do tipo de aplicação esperada. A perda de coloração do polímero pode indicar a degradação do grupo tiocarbonila do agente RAFT, que ocorre comumente se o material for exposto à luz ou temperatura elevada por longos períodos. Embora a obtenção de um polímero com cor possa não influenciar a sua aplicação em certas áreas (como na liberação controlada de fármacos por nano-cápsulas/ partículas poliméricas), em outras aplicações isso pode representar uma grande desvantagem, como no caso da obtenção de comódites. Embora seja possível degradar o grupo tiocarbonila, a completa eliminação de cor do polímero muitas vezes pode ser difícil.

\section{Conclusão}

A técnica de polimerização RAFT constitui sem dúvida uma das mais versáteis técnica de polimerização via radicais livres viva/controlada. Isso se traduz no crescente número de publicações e também na adaptação da técnica para ser usada em diversos tipos de processos de polimerização, o que inclui as polimerizações em miniemulsão. Conforme mostrado, a polimerização RAFT em miniemulsão vem sendo estudada em sistemas diretos e inversos, com diversos tipos de monômeros e comonômeros, para os mais variados tipos de aplicações. Devido às características únicas da técnica de polimerização RAFT, o uso dessa metodologia em sistemas dispersos, como as miniemulsões, se tornou uma rota muito atrativa para a preparação de nanopartículas poliméricas com arquitetura definida. A despeito disso, não existem usos comerciais relevantes dessa técnica no momento, por causa das menores taxas de reação e menores massas molares médias do produto final obtido. No entanto, a possibilidade de controlar com grande precisão a composição de nanopartículas poliméricas e a flexibilidade química conferida pelo grupamento tiocarbonila para funcionalização posterior das nanopartículas produzidas em miniemulsão, têm permitido o uso da técnica de polimerização RAFT 
em miniemulsão para o desenvolvimento de novos materiais poliméricos, principalmente aqueles voltados às aplicações biotecnológicas.

\section{Agradecimentos}

Os autores agradecem ao CNPq (Conselho Nacional de Desenvolvimento Científico e Tecnológico) e à FAPERJ (Fundação Carlos Chagas Filho de Amparo à Pesquisa do Estado do Rio de Janeiro) pelo apoio financeiro e pelas bolsas de estudo.

\section{Referências Bibliográficas}

1. Staudinger, H. - Ber. Dtsch. Chem. Ges., 53, p.1073 (1920).

2. Mülhaupt, R. - Angew. Chem. Int. Ed., 43, p.1054 (2004). http://dx.doi.org/10.1002/anie.200330070

3. Odian, G. - "Principles of Polymerization", 4th. ed., New York (2004). http://dx.doi.org/10.1002/047147875X

4. Tharanathan, R. N. - Trends Food Sci. Technol., 14, p.71 (2003). http://dx.doi.org/10.1016/S0924-2244(02)00280-7

5. Rapoport, N. - Prog. Polym. Sci., 32, p.962 (2007). http:// dx.doi.org/10.1016/j.progpolymsci.2007.05.009

6. Oliveira, M. A. M. - "Produção de Micropartículas e Nanopartículas Poliméricas para Aplicações Biomédicas em Sistemas Heterogêneos de Polimerização", Tese de Doutorado, Universidade Federal do Rio de Janeiro, Brasil (2011)

7. Moad, G.; Rizzardo, E. \& Thang, S. H. - Aust. J. Chem., 58, p.379 (2005). http://dx.doi.org/10.1071/CH05072

8. Moad, G.; Rizzardo, E. \& Thang, S. H. - Aust. J. Chem., 59, p.669 (2006). http://dx.doi.org/10.1071/CH06250

9. Moad, G.; Rizzardo, E. \& Thang, S. H. - Aust. J. Chem., 62, p.1402 (2009). http://dx.doi.org/10.1071/CH09311

10. Moad, G.; Rizzardo, E. \& Thang, S. H. - Aust. J. Chem., 65, p.985 (2012). http://dx.doi.org/10.1071/CH12295

11. Machado, F.; Lima, E. L. \& Pinto, J. C. - Polímeros, 17, p.166 (2007). http://dx.doi.org/10.1590/S010414282007000200016

12. Goto, A. \& Fukuda, T. - Prog. Polym. Sci. (Oxford), 29, p.329 (2004). http://dx.doi.org/10.1016/j. progpolymsci.2004.01.002

13. Zetterlund, P. B.; Kagawa, Y. \& Okubo, M. - Chem. Rev., 108, p.3747 (2008). http://dx.doi.org/10.1021/ cr800242x

14. Szwarc, M.; Levy, M. \& Milkovich, R. - J. Am. Chem. Soc., 78, p.2656 (1956). http://dx.doi.org/10.1021/ ja01592a101

15. Boyer, C.; Bulmus, V.; Davis, T. P.; Ladmiral, V.; Liu, J. \& Perrier, S. - Chem. Rev., 109, p.5402 (2009). http://dx.doi. org/10.1021/cr9001403

16. Barner-Kowollik, C. - "Handbook of RAFT Polymerization", Wiley-VCH, Sydney (2008). http:// dx.doi.org/10.1002/9783527622757

17. Boyer, C.; Stenzel, M. H. \& Davis, T. P. - J. Polym. Sci. Part A: Polym. Chem., 49, p.551 (2011). http://dx.doi. org/10.1002/pola.24482

18. Chiefari, J.; Chong, Y. K.; Ercole, F.; Krstina, J.; Jeffery, J.; Le, T. P. T.; Mayadunne, R. T. A.; Meijs, G. F.; Moad, C. L.; Moad, G.; Rizzardo, E. \& Thang, S.
H. - Macromolecules, 31, p.5559 (1998). http://dx.doi. org/10.1021/ma9804951

19. Fischer, H. - "Advances in Controlled/Living Radical Polymerization", American Chemical Society, Washington, p.704 (2003). (ACS Symposium Series 854).

20. Braun D.; Cherdron, H.; Rehahn, M.; Ritter, H. \& Voit, B. - "Polymer Synthesis: Theory and Practice", p.1-401 (2005).

21. Charmot, D.; Corpart, P.; Adam, H.; Zard, S. Z.; Biadatti, T. \& Bouhadir, G. - Macromol. Symp., 150, p.23 (2000). http://dx.doi. org/10.1002/1521-3900(200002)150:1\%3C23::AIDMASY23\%3E3.0.CO;2-E

22. Quinn, J. F.; Davis, T. P.; Barner, L. \& Barner-Kowollik, C. - Polymer, 48, p.6467 (2007). http://dx.doi.org/10.1016/j. polymer.2007.08.043

23. Oliveira, M. A. M.; Boyer, C.; Nele, M.; Pinto, J. C.; Zetterlund, P. \& Davis, T. P. - Macromolecules, 44, p.7167 (2011). http://dx.doi.org/10.1021/ma201531w

24. Pallares, J.; Jaramillo-Soto, G.; Flores-Cataño, C.; Lima, E. V.; Lona, L. M. F. \& Penlidis, A. - J. Macromol. Sci. Pure Appl. Chem., 43, p.1293 (2006). http://dx.doi. org/10.1080/10601320600814614

25. De Sordi, M. L. T.; Ceschi, M. A.; Petzhold, C. L. \& Müller, A. H. E. - Macromol. Rapid Commun., 28, p.63 (2007). http://dx.doi.org/10.1002/marc.200600641

26. Dos Santos, A. M.; Pohn, J.; Lansalot, M. \& D’Agosto, F. - Macromol. Rapid Commun., 28, p.1325 (2007). http:// dx.doi.org/10.1002/marc.200700146

27. Florenzano, F. H. - Polímeros, 18, p.100 (2008). http:// dx.doi.org/10.1590/S0104-14282008000200006

28. Santos, A. M. D.; Bris, T. L.; Graillat, C.; D’Agosto, F. \& Lansalot, M. - Macromolecules, 42, p.946 (2009). http:// dx.doi.org/10.1021/ma802117h

29. De Oliveira, A. M.; De Oliveira, P. C.; Dos Santos, A. M.; Ambrosio Zanin, M. H. \& Ré, M. I. - Braz. J. Phys., 39, p.217 (2009). http://dx.doi.org/10.1590/S010397332009000200015

30. Sordi, M. L. T.; Riegel, I. C.; Ceschi, M. A.; Müller, A. H. E. \& Petzhold, C. L. - Eur. Polym. J., 46, p.336 (2010). http://dx.doi.org/10.1016/j.eurpolymj.2009.09.017

31. Tebaldi, M. L. D. S.; Chaparro, T. C. \& Santos, A. M. - "Tri-block copolymers obtained by RAFT polymerization: A promising material for drug-delivery systems", in: 5th International Materials Symposium MATERIAiS 2009 - 14th meeting of SPM - Sociedade Portuguesa de Materiais, v.636, p.76, Lisbon (2010).

32. De Sordi, M. L. T.; De Oliveira Da Silva, E.; Ceschi, M. A. \& Petzhold, C. L. - React. Funct. Polym., 71, p.648 (2011). http://dx.doi.org/10.1016/j.reactfunctpolym.2011.02.005

33. De Souza, V. V.; Noronha, M. L. D. C.; Almeida, F. L. A.; Prado, C. S.; Doriguetto, A. N. \& Florenzano, F. B. - Polym. Bull., 67, p.875 (2011). http://dx.doi.org/10.1007/s00289011-0508-x

34. Moad, G.; Chiefari, B. J.; Chong, B. Y.; Krstina, J.; Mayadunne, R. T. A.; Postma, A.; Rizzardo, E. \& Thang, S. H. - Polym. Int., 49, p.993 (2000). http://dx.doi. org/10.1002/1097-0126(200009)49:9\%3C993::AIDPI506\%3E3.0.CO;2-6 
35. De-Brouwer, H.; Tsavalas, J. G.; Schork, F. J. \& Monteiro, M. J. - Macromolecules, 33, p.9239 (2000). http://dx.doi. org $/ 10.1021 / \mathrm{ma} 001205 \mathrm{v}$

36. Herk, A. M. - "Chemistry and Technology of Emulsion Polymerisation", Blackwell Publishing, p.1-324 (2008).

37. Antonietti, M. \& Landfester, K. - Prog. Polym. Sci. (Oxford), 27, p.689 (2002). http://dx.doi.org/10.1016/ S0079-6700(01)00051-X

38. Harkins, W. - J. Chem. Phys., 13, p.381 (1945). http:// dx.doi.org/10.1063/1.1724054

39. Harkins, W. - J. Chem. Phys., 14, p.47 (1946). http://dx.doi. org/10.1063/1.1724062

40. Harkins, W. \& Stearns, R. - J. Chem. Phys., 14, p.215 (1946). http://dx.doi.org/10.1063/1.1724121

41. Harkins, W. - J. Am. Chem. Soc., 69, p.1428 (1947). http:// dx.doi.org/10.1021/ja01198a053

42. Smith, W. \& Ewart, R. - J. Chem. Phys., 16, p.592 (1948). http://dx.doi.org/10.1063/1.1746951

43. Landfester, K. - Adv. Mater., 13, p.765 (2001). http://dx.doi. org/10.1002/1521-4095(200105)13:10\%3C765::AIDADMA765\%3E3.0.CO;2-F

44. Capek, I. - Adv. Colloid Interface Sci., 156, p.35 (2010). http://dx.doi.org/10.1016/j.cis.2010.02.006

45. Schork, F. J.; Luo, Y. W.; Smulders, W.; Russum, J. P.; Butté, A. \& Fontenot, K. - Adv. Polym. Sci., 175, p.129 (2005). http://dx.doi.org/10.1007/b100115

46. Spernath, L. \& Magdassi, S. - Polym. Adv. Technol., 18, p.705 (2007). http://dx.doi.org/10.1002/pat.947

47. Guo, Y.; Liu, J. Q. \& Zetterlund, P. B. - Macromolecules, 43, p.5914 (2010). http://dx.doi.org/10.1021/ma101001j

48. Cheng, S. Q.; Guo, Y. \& Zetterlund, P. B. - Macromolecules, 43, p.7905 (2010). http://dx.doi. org/10.1021/ma101574x

49. Cheng, S.; Ting, S. R. S.; Lucien, F. P. \& Zetterlund, P. B. - Macromolecules, 45, p.1803 (2012). http://dx.doi. org/10.1021/ma202744f

50. Landfester, K.; Bechthold, N.; Tiarks, F. \& Antonietti, M. - Macromolecules, 32, p.5222 (1999). http://dx.doi. org/10.1021/ma990299

51. Landfester, K.; Willert, M. \& Antonietti, M. - Macromolecules, 33, p.2370 (2000). http://dx.doi. org/10.1021/ma991782n

52. Qi, G.; Jones, C. W. \& Schork, F. J. - Macromol. Rapid Commun., 28, p.1010 (2007). http://dx.doi.org/10.1002/ marc. 200700026

53. Tsavalas, J. G.; Schork, F. J.; De Brouwer, H. \& Monteiro, M. J. - Macromolecules, 34, p.3938 (2001). http://dx.doi. org/10.1021/ma001888e

54. Butte, A.; Storti, G. \& Morbidelli, M. - Macromolecules, 34, p.5885 (2001). http://dx.doi.org/10.1021/ma002130y

55. Lansalot, M.; Davis, T. P. \& Heuts, J. P. A. - Macromolecules, 35, p.7582 (2002). http://dx.doi. org/10.1021/ma012214m

56. Vosloo, J. J.; De-Wet-Roos, D. \& Tonge, M. P. \& Sanderson, R. D. - Macromolecules, 35, p.4894 (2002). http://dx.doi. org/10.1021/ma011617j

57. Tonge, M. P.; McLeary, J. B.; Vosloo, J. J.; Sanderson, R. D.; Sanderson, R. D. \& Pasch, H. - Macromol. Symp., 193, p.289 (2003). http://dx.doi.org/10.1002/masy.200390060
58. Uzulina, I.; Gaillard, N.; Guyot, A. \& Claverie, J. - C. R. Chimie, 6, p.1375 (2003). http://dx.doi.org/10.1016/j. crci.2003.10.004

59. McLeary, J. B.; Tonge, M. P.; De Wet Ross, D.; Sanderson, R. D. \& Klumperman, B. - J. Polym. Sci. Part A: Polym. Chem., 42, p.960 (2004).

60. Yang, L.; Luo, Y. \& Li, B. - Acta Polym. Sin., 3, p.462 (2004).

61. Lee, H.; Lee, J. M.; Shim, S. E.; Lee, B. H. \& Choe, S. - Polymer, 46, p.3661 (2005). http://dx.doi.org/10.1016/j. polymer.2005.03.034

62. Van-Zyl, A. J. P.; Bosch, R. F. P.; McLeary, J. B.; Sanderson, R. D. \& Klumperman, B. - Polymer, 46, p.3607 (2005). http://dx.doi.org/10.1016/j.polymer.2005.03.025

63. Yang, L.; Luo, Y. \& Li, B. - J. Polym. Sci.; Part A: Polym. Chem., 43, p.4972 (2005). http://dx.doi.org/10.1002/ pola. 20968

64. Fukudome, Y.; Terayama, E.; Shiraki, K.; Kawaguchi, H. - "Miniemulsion polymerization using surface-active RAFT agent", p.490 (2006).

65. Huang, X.; Sudol, E. D.; Dimonie, V. L.; Anderson, C. D. \& El-Aasser, M. S. - Macromolecules, 39, p.6944 (2006). http://dx.doi.org/10.1021/ma060789j

66. Luo, Y.; Wang, R.; Yang, L.; Yu, B.; Li, B. \& Zhu, S. - Macromolecules, 39, p.1328 (2006). http://dx.doi. org/10.1021/ma0511301

67. Luo, Y. \& Gu, H. - Macromol. Rapid Commun., 27, p.21 (2006). http://dx.doi.org/10.1002/marc.200500649

68. Matahwa, H.; McLeary, J. B. \& Sanderson, R. D. - J. Polym. Sci., Part A: Polym. Chem, 44, p.427 (2006). http:// dx.doi.org/10.1002/pola.21071

69. Yang, L.; Luo, Y. W. \& Li, B. G. - J. Polym. Sci.; Part A: Polym. Chem., 44, p.2293 (2006). http://dx.doi. org/10.1002/pola.21340

70. Yang, L.; Luo, Y. \& Li, B. - Polymer, 47, p.751 (2006). http://dx.doi.org/10.1016/j.polymer.2005.11.054

71. Yu, Z. Q.; Ji, X. L. \& Ni, P. H. - Colloid Polym. Sci., 285, p.211 (2006). http://dx.doi.org/10.1007/s00396-006-15521

72. Lu, F.; Luo, Y. \& Li, B. - Macromol. Rapid Commun., 28, p.868 (2007). http://dx.doi.org/10.1002/marc.200600823

73. Luo, Y. \& Gu, H. - Polymer, 48, p.3262 (2007). http:// dx.doi.org/10.1016/j.polymer.2007.03.042

74. McLeary, J. B.; Tonge, M. P.; De-Wet-Roos, D.; Sanderson, R. D. \& Klumperman, B. - J. Polym. Sci.; Part A: Polym. Chem., 42, p.960 (2004). http://dx.doi.org/10.1002/ pola. 11042

75. Shao, Y. J.; Ni, P. H.; Ji, X. L. \& Yu, Z.-Q. - Chem. J. Chinese U., 25, p.2176 (2004).

76. Shim, S. E.; Lee, H. \& Choe, S. - Macromolecules, 37, p.5565 (2004). http://dx.doi.org/10.1021/ma049930j

77. Guo, T. Y.; Tang, D. L.; Zhu, J. W.; Song, M. D. \& Zhang, B. H. - Chinese Chem. Lett., 17, p.1247 (2006).

78. Zhou, X.; Ni, P. \& Yu, Z. - Polymer, 48, p.6262 (2007). http://dx.doi.org/10.1016/j.polymer.2007.08.053

79. Feng, H.; Zhao, Y.; Pelletier, M; Dan, Y. \& Zhao, Y. - Polymer, 50, p.3470 (2009). http://dx.doi.org/10.1016/j. polymer.2009.06.017

80. Yang, L.; Luo, Y.; Liu, X. \& Li, B. - Polymer, 50, p.4334 (2009). http://dx.doi.org/10.1016/j.polymer.2009.07.002 
81. Qi, G.; Eleazer, B.; Jones, C. W. \& Schork, J. - Macromolecules, 42, p.3906 (2009). http://dx.doi. org/10.1021/ma802741u

82. Lu, F.; Luo, Y.; Li, B.; Zhao, Q. \& Schork, F. J. - Macromolecules, 43, p.568 (2010). http://dx.doi. org/10.1021/ma902058b

83. Ouyang, L.; Wang, L. \& Schork, F. J. - Macromol. Chem. Phys., 211, p.1977 (2010). http://dx.doi.org/10.1002/ macp. 201000213

84. Ouyang, L.; Wang, L. \& Schork, F. J. - Polymer, 52, p.63 (2011). http://dx.doi.org/10.1016/j.polymer.2010.10.063

85. Ouyang, L.; Wang, L. \& Schork, F. J. - Macromol. React. Eng., 5, p.163 (2011). http://dx.doi.org/10.1002/ mren.201000050

86. Wang, Y.; Jiang, G.; Zhang, M.; Wang, L.; Wang, R. \& Sun, X. - Soft Matter., 7, p.5348 (2011). http://dx.doi. org/10.1039/c0sm01534b

87. Smolders, W. W.; Jones, C. W.; Schork, F. J. - Macromolecules, 37, p.9345 (2004). http://dx.doi. org/10.1021/ma0487204

88. Smulders, W. W.; Jones, C. W. \& Schork, F. J. - AIChE J., 51, p.1009 (2005). http://dx.doi.org/10.1002/aic.10363

89. Qi, G. G.; Jones, C. W. \& Schork, J. F. - Ind. Eng. Chem. Res., 45, p.7084 (2006). http://dx.doi.org/10.1021/ ie060293q

90. Tobita, H. \& Yanase, F. - Macromol. Theory Simul., 16, p.476 (2007). http://dx.doi.org/10.1002/mats.200700007

91. Tobita, H. - Macromol. Symp., 261, p.36 (2008).

92. Tobita, H. - Macromol. Theory Simul., 18, p.120 (2009). http://dx.doi.org/10.1002/mats.200800070

93. Tobita, H. - Macromol. Theory Simul., 18, p.108 (2009). http://dx.doi.org/10.1002/mats.200800069

94. Tobita, H. - Macromol. Symp., 288, p.16 (2010).

95. Tobita, H. - Macromol. React. Eng., 4, p.643 (2010). http:// dx.doi.org/10.1002/mren.201000029

96. Tobita, H. - Polymers, 3, p.1944 (2011). http://dx.doi. org/10.3390/polym3041944

97. Tobita, H. - Macromol. Theory Simul., 20, p.709 (2011). http://dx.doi.org/10.1002/mats.201100035

98. Russum, J. P.; Jones, C. W. \& Schork, F. J. - Macromol. Rapid Commun., 25, p.1064 (2004). http://dx.doi. org/10.1002/marc.200400086

99. Russum, J. P.; Jones, C. W. \& Schork, F. J. - Ind. Eng. Chem. Res., 44, p.2484 (2005). http://dx.doi.org/10.1021/ ie $040136 w$

100. Russum, J. P.; Jones, C. W. \& Schork, F. J. - AlChE J., 52, p.1566 (2006). http://dx.doi.org/10.1002/aic.10730

101. Zhang, F.; Ni, P.; Xiong, Q. \& Yu, Z. - J. Polym. Sci., Part A: Polym. Chem, 43, p.2931 (2005). http://dx.doi. org/10.1002/pola.20759

102. Qinghua, Z.; Xiaoli, Z.; Fengqiu, C.; Ying, S. \& Qiongyan, W. - J. Polym. Sci.; Part A: Polym. Chem., 45, p.1585 (2007). http://dx.doi.org/10.1002/pola.21930

103. Guo, T. Y.; Tang, D.; Song, M. \& Zhang, B. - J. Polym. Sci., Part A: Polym. Chem., 45, p.5067 (2007). http://dx.doi. org/10.1002/pola.22249

104. Zhou, X. D.; Ni, P. H.; Yu, Z. Q. \& Zhang, F. - J. Polym. Sci.; Part A: Polym. Chem., 45, p.471 (2007). http://dx.doi. org/10.1002/pola.21861
105. Zhang, Q. H.; Zhan, X. L. \& Chen, F. Q. - Chem. J. Chinese U., 30, p.427 (2009).

106. Zhang, Q.; Wang, Q.; Luo, Z.; Zhan, X. \& Chen, F. - Polym. Eng. Sci., 49, p.1818 (2009). http://dx.doi.org/10.1002/ pen.21419

107. Bussels, R.; Bergman-Gottgens, C.; Meuldijk, J. \& Koning, C. E. - Macromolecules, 37, p.9299 (2004). http://dx.doi. org/10.1021/ma0485787

108. Bussels, R.; Bergman-Gottgens, C.; Meuldijk, J. \& Koning, C. - Polymer, 46, p.8546 (2005). http://dx.doi. org/10.1016/j.polymer.2005.02.126

109. Luo, Y.; Liu, B.; Wang, Z.; Gao, J. \& Li, B. - J. Polym. Sci., Part A: Polym. Chem, 45, p.2304 (2007). http://dx.doi. org/10.1002/pola.21999

110. Simms, R. W.; Davis, T. P. \& Cunningham, M. F. - Macromol. Rapid Commun., 26, p.592 (2005). http:// dx.doi.org/10.1002/marc.200400652

111. Russum, J. P.; Barbre, N. D.; Jones, C. W. \& Schork, F. J. - J. Polym. Sci. Part A: Polym. Chem., 43, p.2188 (2005). http://dx.doi.org/10.1002/pola.20681

112. Jiang, B.; Zhang, Q. H.; Zhan, X. L. \& Chen, F. Q. - Chinese Chem. Lett., 20, p.733 (2009). http://dx.doi.org/10.1016/j. cclet.2008.12.023

113. Pham, B. T. T.; Nguyen, D.; Ferguson, C. J.; Hawkett, B. S.; Serelis, A. K. \& Such, C. H. - Macromolecules, 36, p.8907 (2003). http://dx.doi.org/10.1021/ma035175i

114. Luo, Y. \& Liu, X. - J. Polym. Sci. Part A: Polym. Chem., 42, p.6248 (2004). http://dx.doi.org/10.1002/pola.20478

115. Bowes, A.; Mcleary, J. B. \& Sanderson, R. D. - J. Polym. Sci.; Part A: Polym. Chem., 45, p.588 (2007). http://dx.doi. org/10.1002/pola.21827

116. Wang, Z. X.; Zhang, Q. H.; Yu, Y. T.; Zhan, X. L.; Chen, F. Q. \& Xiong, J. H. - Chinese Chem. Lett., 21, p.1497 (2010). http://dx.doi.org/10.1016/j.cclet.2010.06.001

117. Wang, Y.; Jiang, G.; Sun, X.; Ding, M.; Hu, H. \& Chen, W. - Polym. Chem., 1, p.1638 (2010). http://dx.doi. org/10.1039/c0py00170h

118. Changhuai, Y.; Yingwu, L. \& Xuesong, L. - Polymer, 52, p.683 (2011). http://dx.doi.org/10.1016/j.polymer.2010.12.030

119. Yu, Y.; Zhan, X.; Zhang, Q. \& Chen, F. - Polym. Eng. Sci., 51, p.1041 (2011). http://dx.doi.org/10.1002/ pen.21921

120. Yu, Y.; Zhang, Q.; Zhan, X. \& Chen, F. - J. Appl. Polym. Sci., 127, p.2557 (2012)

121. Xiong, Q.; Ni, P.; Zhang, F. \& Yu, Z. - Polym. Bull., 53, p.1 (2004). http://dx.doi.org/10.1007/s00289-004-0308-7

122. Sun, Z. \& Luo, Y. - Soft Matter., 7, p.871 (2011). http:// dx.doi.org/10.1039/c0sm00983k

123. Al-Bagoury, M.; Buchholz, K. \& Yaacoub, E. J. - Polym. Adv. Techn., 18, p.313 (2007). http://dx.doi.org/10.1002/ pat.888

124. Xu, W.; Cheng, Z.; Zhang, L.; Zhang, Z.; Zhu, J.; Zhou, N. \& Zhu, X. - J. Polym. Sci. Part A: Polym. Chem., 48, p.1324 (2010). http://dx.doi.org/10.1002/pola.23893

125. Chen, H. \& Luo, Y. - Macromol. Chem. Phys., 212, p.737 (2011). http://dx.doi.org/10.1002/macp.201000664 
126. Chiellini, E.; Sunamoto, J.; Migliaresi, C.; Ottenbrite, R. M. \& Cohn, D. - "Biomedical Polymers and Polymer Therapeutics", Kluwer Academic Publishers, p.1-470 (2002).

127. Oh, J. K.; Siegwart, D. J.; Lee, H.; Sherwood, G.; Peteanu, L.; Hollinger, JO.; Kataoka, K. \& Matyjaszewski, K. - J. Am. Chem. Soc., 129, p.5939 (2007). http://dx.doi. org/10.1021/ja0691501

128. Oh, J. K.; Drumright, R.; Siegwart, D. J. \& Matyjaszewski, K. - Prog. Polym. Sci., 33, p.448 (2008). http://dx.doi. org/10.1016/j.progpolymsci.2008.01.002

129. Hoare, T. R. \& Kohane, D. S. - Polymer, 49, p.1993 (2008). http://dx.doi.org/10.1016/j.polymer.2008.01.027

130. Ryu, J. H.; Chacko, R. T.; Jiwpanich, S.; Bickerton, S.; Babu, R. P. \& Thayumanavan, S. - J. Am. Chem. Soc., 132, p.17227 (2010). http://dx.doi.org/10.1021/ja1069932

131. Landfester, K. - Angew. Chem. Int. Ed., 48, p.4488 (2009). http://dx.doi.org/10.1002/anie.200900723

132. Faucheu, J.; Gauthier, C.; Chazeau, L.; Cavaillé, J.-Y.; Mellon, V. \& Lami, E. B. - Polymer, 51, p.6 (2010). http:// dx.doi.org/10.1016/j.polymer.2009.11.044

133. Van Berkel, K. Y. \& Hawker, C. J. - J. Polym. Sci. Part A: Polym. Chem., 48, p.1594 (2010). http://dx.doi. org/10.1002/pola.23917

134. Landfester, K. - Macromol. Rapid Commun., 22, p.896 (2001). http://dx.doi.org/10.1002/15213927 ( 20010801 ) 22:12\%3C 896 : : A I D MARC896\%3E3.0.CO;2-R

135. Asua, J. M. - Prog. Polym. Sci., 27, p.1283 (2002). http:// dx.doi.org/10.1016/S0079-6700(02)00010-2

136. Braunecker, W. A. \& Matyjaszewski, K. - Prog. Polym. Sci., 32, p.93 (2007). http://dx.doi.org/10.1016/j. progpolymsci.2006.11.002

137. Ide, N. \& Fukuda, T. - Macromolecules, 32, p.95 (1999). http://dx.doi.org/10.1021/ma9805349

138. Zetterlund, P. B.; Alam, M. N.; Minami, H. \& Okubo, M. - Macromol. Rapid Commun., 26, p.955 (2005). http:// dx.doi.org/10.1002/marc. 200500100

139. Saka, Y.; Zetterlund, P. B. \& Okubo, M. - Polymer, 48, p.1229 (2007). http://dx.doi.org/10.1016/j.polymer.2007.01.029

140. Cunningham, M. F. - Prog. Polym. Sci., 33, p.365 (2008). http://dx.doi.org/10.1016/j.progpolymsci.2007.11.002
141. Gao, H. \& Matyjaszewski, K. - Prog. Polym. Sci. (Oxford), 34, p.317 (2009). http://dx.doi.org/10.1016/j. progpolymsci.2009.01.001

142. Kanagasabapath, S.; Claverie, J. \& Uvilina, I. - "Synthesis of well defined tridlock copolymer by reversible addition fragmentation chain transfer (raft) polymerization in emulsion", American Chemical Society, Polymer Preprints, Division of Polymer Chemistry, v.40, p.1080 (1999).

143. Biasutti, J. D.; Davis, T. P.; Lucien, F. P. \& Heuts, J. P. A. - J. Polym. Sci. Part A: Polym. Chem., 43, p.2001 (2005). http://dx.doi.org/10.1002/pola.20673

144. Liu, S. Y.; Hermanson, K. D. \& Kaler, E. W. - Macromolecules, 39, p.4345 (2006). http://dx.doi. org/10.1021/ma0526950

145. Chang, C.-W.; Bays, E.; Tao, L.; Alconcel, S. N. S. \& Maynard, H. D. - Chem. Commun., 24, p.3580 (2009).

146. Pissuwan, D.; Boyer, C.; Gunasekaran, K.; Davis, T. P. \& Bulmus, V. - Biomacromolecules, 11, p.412 (2010). http:// dx.doi.org/10.1021/bm901129x

147. Xu, J.; He, J.; Fan, D.; Wang, X. \& Yang, Y. - Macromolecules, 39, p.8616 (2006). http://dx.doi. org/10.1021/ma061961m

148. Baussard, J. F.; Habib-Jiwan, J. L.; Laschewsky, A.; Mertoglu, M. \& Storsberg, J. - Polymer, 45, p.3615 (2004). http://dx.doi.org/10.1016/j.polymer.2004.03.081

149. Thomas, D. B.; Convertine, A. J.; Hester, R. D.; Lowe, A. B. \& McCormick, C. L. - Macromolecules, 37, p.1735 (2004). http://dx.doi.org/10.1021/ma035572t

150. Chong, Y. K.; Moad, G.; Rizzardo, E. \& Thang, S. H. - Macromolecules, 40, p.4446 (2007). http://dx.doi. org/10.1021/ma062919u

151. Cao, M.; Wang, J.-Q.; Chen, P.-C.; Xu, J. T. \& Fan, Z. Q. - J. Polym. Sci. Part A: Polym. Chem., 48, p.3834 (2010). http://dx.doi.org/10.1002/pola.24169

152. Postma, A.; Davis, T. P.; Moad, G. \& O'Shea, M. S. - Macromolecules, 38, p.5371 (2005). http://dx.doi. org/10.1021/ma050402x

Enviado: 10/01/13

Reenviado: $23 / 03 / 13$

Aceito: $25 / 03 / 13$ 